\title{
AVALIAÇÃO AGRONÔMICA DE PARENTAIS E HÍBRIDOS DE MARACUJAZEIRO- AMARELO ${ }^{1}$
}

\author{
CLÁUDIA GARCIA NEVES ${ }^{2}$, ONILDO NUNES DE JESUS ${ }^{3}$ \\ CARLOS ALBERTO DA SILVA LEDO ${ }^{4}$, EDER JORGE DE OLIVEIRA ${ }^{5}$
}

RESUMO- O presente trabalho objetiva determinar o potencial agronômico de genótipos de maracujazeiroamarelo, visando a identificar e selecionar híbridos promissores. O experimento foi conduzido em área de produção no município de Cruz das Almas (BA), em delineamento de blocos casualizados, com três repetições, 41 genótipos (30 híbridos e 11 parentais), com parcela de 4 plantas. As características avaliadas foram: produtividade; número de frutos; massa média de frutos; espessura de casca; rendimento de suco; produtividade de suco e teor de sólidos solúveis totais. Houve diferença significativa entre os genótipos a $1 \%$ de probabilidade pelo teste $\mathrm{F}$, para todas as variáveis em estudo, exceto para a característica rendimento de suco $(\mathrm{p}<0,06)$. Os genótipos avaliados apresentaram altas amplitudes para todas as características, o que indica situação favorável para a seleção dos melhores para recomendação. Contudo, observou-se que a maioria das características adequadas para uma boa cultivar de maracujazeiro está presente em diferentes genótipos, com existência de algumas correlações indesejáveis. Dentre as correlações genotípicas positivas de maior importância, estão PROD x NF $(0,78)$ e PROD x PRSUC $(0,81)$. Entretanto, a utilização de índices de seleção de Mulamba \& Mock e a distância genótipo-ideótipo possibilitou a indicação de três híbridos (H09-10, H09-14 e H09-20) que apresentaram médias elevadas e equilibradas para as sete características avaliadas, devendo ser validados em outras regiões de produção do maracujazeiro-amarelo.

Termos para Indexação: Passiflora edulis Sims f. flavicarpa Deg.; melhoramento genético; caracterização físico-química; dialelo.

\section{AGRONOMIC EVALUTION OF PARENTAL AND HYBRID OF YELLOW PASSION FRUIT}

\begin{abstract}
The present study aims to determine the agronomic potential of genotypes of yellow passion fruit, to identify and select promising hybrid. The experiment was conducted in the production area in Cruz das Almas (BA) in a randomized block design with three replications, 41 genotypes ( 30 hybrids and 11 parents), in a share of four plants. The characteristics evaluated were: yield, number of fruits, average mass fruit, peel thickness, juice yield, and total soluble solids. There were significant differences between genotypes for the $\mathrm{F}$ test for all variables studied, except for juice yield $(\mathrm{p}<0.06)$. High amplitudes for all traits were observed, showing favorable situation to select the best genotypes for recommendation. However, it was observed that the most suitable traits for a good yellow passion fruit cultivar are presented in different genotypes, with existence of some undesirable correlations. Among the positive genotypic correlation of greater importance are yield $\mathrm{x}$ number of fruits $(0.78)$ and yield $\mathrm{x}$ juice productivity $(0.81)$. However, the use of the selection indexes of Mulamba \& Mock (MM) and genotype-ideotype distance, allowed the appointment of three hybrids (H09-10, H09-14 and H09-20) with high average and balanced averages to the seven traits evaluated and should be validated in other regions of production of yellow passion fruit.
\end{abstract}

Index terms: Passiflora edulis Sims f. flavicarpa Deg.; breeding; physico-chemical characterization; diallel.

\footnotetext{
${ }^{1}$ (Trabalho 205-12). Recebido em: 04-07-2012. Aceito para publicação em: 29-11-2012.

${ }^{2}$ Mestre em Ciências Agrárias. Universidade Federal do Recôncavo da Bahia, Câmpus Universitário de Cruz das Almas, 44380-000 Cruz das Almas-BA. E-mail: claudia-garcia23@hotmail.com.br

${ }^{3}$ Dr. Pesquisador da Embrapa Mandioca e Fruticultura, Rua da Embrapa, s/n, Caixa Postal 007, 44380-000 Cruz das Almas-BA. E mail: onildo.nunes@embrapa.br

${ }^{4}$ Dr. Pesquisador da Embrapa Mandioca e Fruticultura, Rua da Embrapa, s/n, Caixa Postal 007, 44380-000 Cruz das Almas-BA. E mail: 1carlos.ledo@embrapa.br

${ }^{5}$ Dr. Pesquisador da Embrapa Mandioca e Fruticultura, Rua da Embrapa, s/n, Caixa Postal 007, 44380-000 Cruz das Almas-BA. E-mail: eder@cnpmf.embrapa.br
} 


\section{INTRODUÇÃO}

Estima-se que 95\% da produção nacional de maracujazeiro seja oriunda apenas da forma amarela, também conhecido com maracujazeiro-azedo (P. edulis Sims. f. flavicarpa Deg.) (HAFLE et al., 2009). A produtividade média alcançada nos pomares brasileiros é muito baixa $\left(14,7\right.$ t.ha $\left.^{-1}\right)$, comparada ao potencial produtivo da espécie que pode chegar a mais de 40 t.ha $^{-1}$ (FREITAS et al., 2011). Assim, a utilização de genótipos superiores, oriundos de programas de melhoramento genético, pode resultar em aumento deste potencial produtivo.

A obtenção de híbridos como produto do melhoramento tem sido recentemente adotada nos programas de melhoramento do maracujazeiro, embora ainda exista muito a ser reportado sobre o comportamento produtivo e a qualidade de frutos deste tipo de material genético. Por outro lado, a seleção simultânea para diversas características agronômicas de importância, visando à obtenção de bons híbridos, é um dos grandes desafios para os programas de melhoramento do maracujazeiro, tendo em vista que a maioria delas tem herança quantitativa, e por isso possuem forte influência ambiental, além de serem correlacionadas, de tal forma que a seleção em uma característica provoca uma série de mudanças em outras (FREITAS et al., 2012).

O uso de índices de seleção permite combinar as múltiplas informações de determinado genótipo, possibilitando a seleção com base em um complexo de variáveis que reúnam atributos de interesse, mesmo para aquelas características com efeito antagônico (SANTOS et al., 2007). No caso do maracujazeiro, a utilização de índices de seleção tem sido realizada em progênies meios-irmãos (OLIVEIRA et al., 2008; SILVA et al., 2009), irmãos completos (GONÇALVES et al., 2007) e em acessos de germoplasma (FREITAS et al., 2011), com a intuito de melhorar a média populacional em futuros ciclos de cruzamentos. Entretanto, esta estratégia também pode ser utilizada para indicação de genótipos que combinem diversas características agronômicas para fins de recomendação. Assim, o presente trabalho objetiva determinar o potencial agronômico de genótipos de maracujazeiro-amarelo desenvolvidos pela Embrapa Mandioca e Fruticultura, visando a identificar e a selecionar híbridos promissores.

\section{MATERIAL E MÉTODOS}

$\mathrm{O}$ experimento foi conduzido em área de produção, no município de Cruz das Almas - BA (12 $48^{\prime} 38^{\prime \prime}$ S e $39^{\circ} 6^{\prime} 26^{\prime \prime} \mathrm{W}$, a $220 \mathrm{~m}$ de altitude), de clima tropical quente e úmido, em delineamento de blocos casualizados, com três repetições, 41 tratamentos (11 parentais e 30 híbridos), com parcela de quatro plantas. O plantio das mudas foi realizado em novembro de 2009 , em espaçamento de 2,6 m entre linhas e 3,7 m entre plantas. O sistema de condução utilizado foi de espaldeira vertical em condição de sequeiro. Durante a condução do experimento, foram realizados os tratos culturais recomendados à cultura.

Os genótipos de maracujazeiro estudados são oriundos de cruzamentos entre parentais selecionados pelo Programa de Melhoramento Genético do Maracujazeiro, da Embrapa Mandioca e Fruticultura. Para isso, foram realizados cruzamentos entre 11 parentais selecionados com base na sua alta produtividade e na qualidade de frutos.

As avaliações dos genótipos foram efetuadas durante todo o ciclo de produção da cultura, embora a colheita dos frutos para as análises físico-químicas tenha sido concentrada no período de abril a junho de 2010. As características avaliadas foram: 1) produtividade de frutos em t.ha-1 (PROD); 2) número de frutos por parcela (NF); 3) massa média de frutos (MF), em gramas; 4) espessura de casca (EC), mensurada em milímetros na porção mediana dos frutos (cortados transversalmente); 5) rendimento de suco (REND), mensurado pela relação entre massa da polpa/massa do fruto x $100 ; 6$ ) produtividade de suco em t.ha- ${ }^{-1}$ (PRSUC), mensurado pela relação rendimento x produtividade de frutos; e 7) teor de sólidos solúveis totais (SST), mensurado em refratômetro portátil RTA-50 (Instrutherm).

Os dados foram submetidos à análise de variância, de acordo com o modelo $Y_{i j}=\mu+G_{i}+$ $B_{j}+C_{i j}$, em que: $Y_{i j}=$ observação obtida na parcela com i-ésimo genótipo no j-ésimo bloco; $\mu=$ média geral; $G_{i}=$ efeito do i-ésimo genótipo; $B_{j}=$ efeito do $j$-ésimo bloco; $\epsilon_{i j}=$ efeito do erro aleatório associado à observação de ordem $i j$. Em seguida, as médias dos genótipos foram comparadas pelo teste de Scott-Knott, a 5\% de probabilidade. Foi realizada correlação genética entre as variáveis analisadas. A magnitude das correlações genéticas foi classificada como: $r=0$ (nula); $0<|r|<0,30$ (fraca); $0,30<|r|$ $<0,60$ (média); $0,60<|\mathrm{r}|<0,90$ (forte); $0,90<|\mathrm{r}|<$ 1 ( fortíssima), e $|\mathrm{r}|=1$ (perfeita). Todas as análises estatísticas foram realizadas com auxílio do programa Genes (CRUZ, 2006).

Para a seleção dos cinco melhores genótipos, utilizaram-se os seguintes índices de seleção: 1) índice da distância genótipo-ideótipo - DGI; e 2) índice baseado na soma de postos - SP (MULAMBA; MOCK, 1978). Para ambos os índices, utilizou-se peso econômico aleatório igual a dois (2) 
para PROD e um (1) para as demais características. Além disso, utilizou-se sentido inverso da seleção para a característica EC, ao aplicar o índice baseado na soma de postos.

\section{RESULTADOS E DISCUSSÃO}

Houve diferença significativa entre os genótipos a $1 \%$ de probabilidade pelo teste $\mathrm{F}$, para todas variáveis em estudo, exceto para a REND $(p<0,06)$. Em relação à qualidade experimental, o coeficiente variação experimental (CVe) variou entre 9,18 e $24,40 \%$ (Tabela 1). De maneira geral, observa-se boa precisão experimental, apesar de a natureza poligênica das características avaliadas sofrer forte influência do ambiente e ser controlada por muitos genes. Além disso, estas estimativas de CVe estão de acordo com observações de outros experimentos com progênies de maracujazeiro-amarelo, onde foram observadas estimativas variando de 4,75 a $22,66 \%$ (NEGREIROS et al., 2008; OLIVEIRA et al., 2008) e 4,81 a 15,08\% em germoplasma de maracujazeiro (FREITAS et al., 2011).

A produtividade média de frutos variou de 24,03 a 43,75 t.ha-1 em 13 meses de produção, com média de 33,91 th.ha ${ }^{-1}$ (Tabela 1). Estas estimativas foram bastante superiores à média nacional, que está em torno de 14 t.ha ${ }^{-1}$. Outros relatos indicam produtividades médias de 23,0 tha ${ }^{-1}$ (ALBUQUERQUE et al., 2009) e 33,57 t.ha-1 (FREITAS et al., 2011). Embora o teste de médias não tenha demonstrado diferença significativa em genótipos com médias variando de 33,06 a 43,75 t.ha-1 ${ }^{-1}$ é possível destacar os híbridos H09-08, H09-10, H09-13 e H09-14, com produtividades acima de 41,41 t.ha-1 (Tabela 2). A superioridade dos híbridos em relação aos parentais pode ser demonstrada pelo fato de que a maioria dos genótipos de melhor desempenho para PROD (84,6\%) são híbridos. O parental GP09-03 também apresentou ótimo desempenho produtivo $\left(39,21\right.$ tha ${ }^{-}$ $\left.{ }^{1}\right)$, constituindo-se em alternativa para uso no sistema de produção da cultura.

Para a característica NF, observou-se variação de 740,25 (H09-18) a 1.553,9 frutos (H09-13), com média de 1.022,59 frutos. A maioria dos genótipos mais produtivos também apresentou maior número de frutos, a exemplo dos híbridos H09-08, H09-10, H09-13 e H09-14 (Tabela 2).

Um dos pontos de grande importância para os frutos destinados ao comércio de frutas frescas refere-se à maior massa de frutos, de tal forma que se garanta a melhor classificação comercial e, por conseguinte, melhores preços. Neste sentido, observou-se que a massa média dos frutos variou de 188 a $299 \mathrm{~g}$, com média de $236,49 \mathrm{~g}$. Esses resultados estão próximos à variação de 170 e $218 \mathrm{~g}$ frutos e 191 e $228 \mathrm{~g}$ fruto $^{-1}$ obtidas por Meletti et al. (2000) e Campos et al. (2007), respectivamente. Frutos com massa média acima de $180 \mathrm{~g}$ possuem ótimo valor comercial para o uso ao natural. Assim, todos os genótipos avaliados (parentais e híbridos) enquadram-se dentro deste padrão de comercialização. Entretanto, merecem destaque os parentais GP09-06 e GP09-11, e os híbridos H09-02, H09-03, H09-05, H09-06, H09-10, H09-14, H09-16, H09-17, H09-18, H09-20, H09-21, H09-24, H09-27, H09-28, H09-29 e H09-30, com MF acima de $240 \mathrm{~g}$ massa (Tabela 2).

Na busca por frutos com melhores qualidades físicas e químicas, a redução da espessura da casca é uma característica de grande importância que deve ser considerada na escolha de novas variedades de maracujazeiro-amarelo (FARIAS et al., 2005). Para a maioria dos genótipos avaliados (56\%), os valores de EC variaram de 5,73 a 7,61 mm. Relatos de outros trabalhos indicam que a característica EC também é bastante variável, sobretudo pela natureza genética dos materiais avaliados, a exemplo da análise de acessos de germoplasma, na qual se observaram valores variando de 6,06 a 7,99 mm (FREITAS et al., 2011).

Os maiores rendimentos de polpa foram observados nos híbridos H09-05 e H09-10 (acima de 35\%). De acordo com Nascimento et al. (1999), o rendimento em suco de frutos destinados à industrialização, deve ser de, no mínimo, $33 \%$ da massa total do fruto. Considerando este índice, apenas os híbridos H09-03; H09-05; H09-07 ; H09-10; H09-15 e H09-20 e o parental GP09-08 seriam selecionados para recomendação para o mercado de agroindústria (Tabela 2). Contudo, as condições ambientais influenciam fortemente na expressão desta característica, o que certamente merece uma avaliação destes genótipos em outros ambientes.

Em relação à PRSUC, 46,3\% dos genótipos apresentaram produtividade acima de 9,8 t.ha ${ }^{-1}$, embora os híbridos H09-05, H09-08, H09-10, H09-15 e H09-20 tenham-se destacado com valores acima de 12,3 tha ${ }^{-1}$ (Tabela 2). Importante destacar que, embora o híbrido H09-03 tenha apresentado a maior MF, este não apresentou maior PRSUC, pelo fato de apresentar uma produtividade mediana de frutos, em comparação com os demais genótipos. A produtividade de suco por área é um parâmetro importante, sobretudo para destinação dos produtos para o mercado de agroindústria, ou mesmo para o mercado de frutas frescas, desde que se possa associar este parâmetro com maior MF.

O teor elevado de SST é uma característica bastante importante para a indústria, pois são necessários cerca de $11 \mathrm{~kg}$ de frutos com SST entre $11 \mathrm{e}$ $12 \%$ para obtenção de $1 \mathrm{~kg}$ de suco concentrado a 50 ${ }^{\circ}$ Brix. Assim, quanto maior o teor de SST, menor a quantidade de frutos necessária para a concentração do suco (NASCIMENTO et al., 2003). Para essa 
característica, observou-se uma amplitude nos dados de 10,01 a $15,16^{\circ}$ Brix. Os parentais GP09-11, GP0904, GP09-08 e o híbrido H09-10 destacaram-se com teores acima de $14{ }^{\circ}$ Brix. Neste caso, com a adoção destes genótipos, seriam necessários apenas $8 \mathrm{~kg}$ de frutos para obter os mesmos $1 \mathrm{~kg}$ de suco concentrado a $50^{\circ}$ Brix. Atualmente, o padrão preconizado para a comercialização dos frutos de maracujazeiro-amarelo está acima de $11^{\circ}$ Brix. Portanto, apenas os genótipos GP09-10 e H09-24 estariam abaixo deste limite mínimo.

Das 21 correlações genotípicas, 43; 19; 33 e $5 \%$ foram significativas como fracas, medianas, fortes e fortíssimas, respectivamente. Pautando a discussão apenas nas correlações genotípicas $\left(\mathrm{r}_{\mathrm{g}}\right)$ acima de 0,30, observa-se que, dentre as de maior importância estão PROD x NF $\left(r_{g}=0,78\right)$ e PROD $x$ PRSUC $\left(r_{g}=0,81\right)$ ( Tabela 3$)^{g}$. Como era de se esperar, o aumento em NF conduz ao aumento de produtividade, conforme também observado por outros autores (OLIVEIRA et al., 2011). Contudo, é importante destacar que o aumento de PROD e PRSUC não está fortemente correlacionado com MF ( $r_{g}=-0,02$ e $-0,15$, respectivamente), o que demonstra que é possível selecionar materiais produtivos com massa de frutos de tamanhos variados. Estas informações têm importante repercussão no desenvolvimento de novas variedades, uma vez que frutos com maior MF são preferidos para o mercado de frutas frescas, enquanto maiores produtividade e rendimento de suco são especialmente importantes para a agroindústria.

O NF está negativamente correlacionado com MF $\left(\mathrm{r}_{\mathrm{g}}=-0,63\right)$. Assim, o aumento no NF promove reduçỗes na dimensão dos frutos que podem comprometer seu uso para o mercado de frutas frescas, que valoriza frutos $3 \mathrm{~A}(6,6$ a $7,5 \mathrm{~mm})$ e $4 \mathrm{~A}(7,6 \mathrm{a}$ $8,5 \mathrm{~mm})$. Também se observou correlação negativa entre EC x (REND e PRSUC) e positiva entre EC x MF. Neste caso, o aumento na MF também conduz ao aumento na $\mathrm{EC}$, como componente indesejável no processo de melhoramento.

Altas correlações genéticas e positivas foram observadas entre REND x (PRSUC e SST) e PRSUC $\mathrm{x}$ SST, demonstrando que o componente rendimento de suco também está relacionado com a qualidade do suco de maracujazeiro-amarelo. Observações desta relação inversa entre REND e EC também foram observadas por outros autores (NASCIMENTO et al., 1999).

De modo geral, ganhos em algumas características que proporcionem aumento nas médias, como PROD e PRSUC, são desejáveis. Porém, em outras características, como EC, busca-se a redução em seus valores. Contudo, a identificação de genótipos que combinem todas estas características é uma tarefa complexa. Por outro lado, a aplicação de índices de seleção pode contribuir para que a seleção seja coerente com os objetivos desejados nos programas de melhoramento, de modo que resulte em ganhos simultâneos e equilibrados.

A seleção dos cinco melhores genótipos para as sete características agronômicas avaliadas, com base no índice de seleção Mulamba \& Mock, demonstrou a possibilidade de indicação de genótipos superiores em 25,02; 15,59; 11,06; 7,41 e 5,10\% para as características PRSUC, NF, PROD, REND e SST, respectivamente, em relação à média da população em estudo. Por outro lado, houve redução da EC em $6,72 \%$ e MF (1,28\%) (Tabela 4). A redução da EC é desejável por possibilitar que maior proporção da massa do fruto esteja relacionada ao conteúdo de suco, mas a redução na MF é indesejável, muito embora com valores inexpressivos. Os genótipos selecionados pelo índice de seleção Mulamba e Mock estão apresentados na Tabela 5. De modo geral, confirma-se o bom desempenho dos híbridos H09-08, H09-10, H09-14, H09-15 e H09-20 para a maioria das características avaliadas.

Em relação ao índice da distância genótipo-ideótipo, foram obtidos ganhos desejáveis que variaram de 2,66 a 24,78\% (NF e PRSUC, respectivamente), e redução na $\operatorname{EC~}(5,63 \%)$ (Tabela 4). Os híbridos H09-10, H09-14 e H09-20 foram comumente selecionados pelos dois índices de seleção, embora os híbridos H09-03 e H09-05 tenham sido selecionados apenas pelo índice da distância genótipo-ideótipo (Tabela 5). Esta não coincidência completa dos genótipos pelos dois índices promoveu uma redução na média dos genótipos selecionados pelo índice de Mulamba \& Mock, para as características PROD, NF, PRSUC e SST, e pequenos ganhos para as características REND e MF.

Ao analisarem um conjunto de acessos de germoplasma de maracujazeiro-amarelo, Freitas et al. (2012) também demonstraram que o índice de Mulamba \& Mock pode proporcionar ganhos simultâneos e satisfatórios para PROD, MF, REND e SST, e redução na severidade das doenças, sendo considerado o melhor índice em comparação com o uso da seleção direta, índice de seleção distância genótipo-ideótipo e índice de Smith \& Hazel. Entretanto, como o principal objetivo do presente trabalho é indicar os melhores híbridos para futuras ações de recomendação de variedades, apenas os três híbridos (H09-10, H09-14 e H09-20) indicados como superiores pelos dois índices de seleção aplicados serão efetivamente validados em outras regiões produtoras. 
TABELA 1-Variância e caracterização dos genótipos de maracujazeiro-amarelo (parentais e híbridos).

\begin{tabular}{cccccccc}
\hline \multirow{2}{*}{ Variáveis } & \multicolumn{7}{c}{ Características agronômicas $^{\mathbf{1}}$} \\
\cline { 2 - 8 } & PROD & NF & EC & MF & REND & PRSUC & SST \\
\hline QM (Genótipos) & $75,17^{* *}$ & $107944,28^{* *}$ & $2,95^{* *}$ & $2401,97^{* *}$ & $109,36^{*}$ & $27,05^{* *}$ & $3,88^{* *}$ \\
Média & 33,91 & 1022,60 & 7,65 & 236,49 & 28,75 & 9,77 & 12,98 \\
Mínimo & 24,03 & 740,25 & 5,73 & 188,08 & 19,27 & 5,75 & 10,01 \\
Máximo & 43,75 & 1553,9 & 9,91 & 299,77 & 36,27 & 15,68 & 15,16 \\
CVe(\%) & 16,57 & 16,40 & 13,40 & 16,39 & 22,10 & 24,40 & 9,18 \\
\hline
\end{tabular}

${ }^{1}$ PROD: produtividade de frutos; NF: número de frutos; EC: espessura de casca; MF: massa de frutos; REND: rendimento de suco; PRSUC: produtividade de suco; e SST: teor de sólidos solúveis totais. ${ }^{2} \mathrm{CVe}$ : Coeficiente de variação experimental, em percentagem. ** e $\mathrm{e}^{*}$, significativo a $1 \%$ e $6 \%$ pelo teste $\mathrm{F}$, respectivamente.

TABELA2- Médias para sete características agronômicas avaliadas em 41 genótipos de maracujazeiro-amarelo.

\begin{tabular}{|c|c|c|c|c|c|c|c|}
\hline \multirow{2}{*}{ Genótipos } & \multicolumn{7}{|c|}{ Características $^{1}$} \\
\hline & PROD & NF & EC & MF & REND & PRSUC & SST \\
\hline GP09-01 & $27,17 b^{2}$ & $1011,72 \mathrm{c}$ & $6,68 \mathrm{a}$ & $188,08 \mathrm{~b}$ & $29,21 \mathrm{~d}$ & $8,00 \mathrm{~b}$ & $13,47 \mathrm{a}$ \\
\hline GP09-02 & $27,89 \mathrm{~b}$ & $910,22 c$ & $6,50 \mathrm{a}$ & $214,73 b$ & $31,47 \mathrm{c}$ & $8,81 \mathrm{~b}$ & $12,80 \mathrm{a}$ \\
\hline GP09-03 & $39,21 \mathrm{a}$ & $1257,73 b$ & $7,89 \mathrm{~b}$ & $218,40 \mathrm{~b}$ & $27,33 \mathrm{e}$ & $10,70 \mathrm{a}$ & $12,35 b$ \\
\hline GP09-04 & $26,72 b$ & $813,56 \mathrm{c}$ & $5,73 a$ & $231,03 b$ & $25,77 f$ & $6,89 b$ & $15,01 \mathrm{a}$ \\
\hline GP09-05 & $35,02 \mathrm{a}$ & $1140,18 b$ & $7,95 \mathrm{~b}$ & $219,80 \mathrm{~b}$ & $19,84 \mathrm{~h}$ & $6,89 \mathrm{~b}$ & $11,16 b$ \\
\hline GP09-06 & $36,54 a$ & $1043,05 \mathrm{c}$ & $8,51 \mathrm{~b}$ & $245,40 \mathrm{a}$ & $29,54 d$ & $10,76 a$ & $13,88 \mathrm{a}$ \\
\hline GP09-07 & $27,47 \mathrm{~b}$ & $849,73 c$ & $6,31 \mathrm{a}$ & $227,49 b$ & $27,37 \mathrm{e}$ & $7,60 \mathrm{~b}$ & $12,95 \mathrm{a}$ \\
\hline GP09-08 & $30,89 \mathrm{~b}$ & $1061,66 \mathrm{c}$ & $7,40 \mathrm{a}$ & $206,93 b$ & $33,32 b$ & $10,35 a$ & $15,13 \mathrm{a}$ \\
\hline GP09-09 & $24,03 b$ & $791,93 c$ & $7,25 \mathrm{a}$ & $213,78 b$ & $29,33 d$ & $6,91 \mathrm{~b}$ & $13,83 \mathrm{a}$ \\
\hline GP09-10 & $31,08 b$ & $1050,87 \mathrm{c}$ & $6,07 \mathrm{a}$ & $208,02 \mathrm{~b}$ & $30,22 \mathrm{c}$ & $9,37 \mathrm{~b}$ & $10,01 b$ \\
\hline GP09-11 & $36,04 a$ & $892,21 \mathrm{c}$ & $9,91 b$ & $285,57 \mathrm{a}$ & $27,45 \mathrm{e}$ & $9,91 \mathrm{a}$ & $14,11 \mathrm{a}$ \\
\hline H09-01 & $36,88 \mathrm{a}$ & $1240,38 b$ & $7,05 \mathrm{a}$ & $210,04 b$ & $31,10 \mathrm{c}$ & $11,51 \mathrm{a}$ & $13,60 \mathrm{a}$ \\
\hline H09-02 & $26,06 \mathrm{~b}$ & $750,22 \mathrm{c}$ & $8,08 \mathrm{~b}$ & $245,43 a$ & $29,51 d$ & $7,84 b$ & $12,78 \mathrm{a}$ \\
\hline H09-03 & $34,16 a$ & $830,89 \mathrm{c}$ & $6,87 \mathrm{a}$ & $290,05 \mathrm{a}$ & $34,12 b$ & $11,67 \mathrm{a}$ & $13,99 a$ \\
\hline H09-04 & $27,25 \mathrm{~b}$ & $806,40 c$ & $6,45 \mathrm{a}$ & $237,65 b$ & $32,92 b$ & $8,85 \mathrm{~b}$ & $12,72 \mathrm{a}$ \\
\hline H09-05 & $37,25 \mathrm{a}$ & $1025,88 \mathrm{c}$ & $7,85 b$ & $254,87 \mathrm{a}$ & $35,16 a$ & $12,94 a$ & $12,40 b$ \\
\hline H09-06 & $33,06 a$ & $889,23 \mathrm{c}$ & $9,06 \mathrm{~b}$ & $261,60 a$ & $23,71 \mathrm{~g}$ & $7,84 b$ & $13,00 \mathrm{a}$ \\
\hline H09-07 & $29,18 b$ & $1056,00 \mathrm{c}$ & $7,55 \mathrm{a}$ & $205,68 \mathrm{~b}$ & $33,90 \mathrm{~b}$ & $9,82 \mathrm{a}$ & $13,24 \mathrm{a}$ \\
\hline H09-08 & $41,41 \mathrm{a}$ & $1462,59 a$ & $6,67 \mathrm{a}$ & $201,36 b$ & $29,58 \mathrm{~d}$ & $12,43 a$ & $13,96 a$ \\
\hline H09-09 & $35,69 a$ & $1091,28 \mathrm{c}$ & $7,49 a$ & $228,93 \mathrm{~b}$ & $30,25 \mathrm{c}$ & $10,93 a$ & $13,36 \mathrm{a}$ \\
\hline H09-10 & $43,75 a$ & $1267,50 \mathrm{~b}$ & $6,63 \mathrm{a}$ & $242,62 \mathrm{a}$ & $36,27 a$ & $15,68 \mathrm{a}$ & $15,16 \mathrm{a}$ \\
\hline H09-11 & $31,96 b$ & $1011,90 \mathrm{c}$ & $8,71 \mathrm{~b}$ & $223,60 \mathrm{~b}$ & $22,59 \mathrm{~g}$ & $7,24 b$ & $12,30 b$ \\
\hline H09-12 & $36,32 \mathrm{a}$ & $1077,90 \mathrm{c}$ & $8,76 \mathrm{~b}$ & $233,13 b$ & $32,30 \mathrm{~b}$ & $11,20 \mathrm{a}$ & $13,92 \mathrm{a}$ \\
\hline H09-13 & $41,51 \mathrm{a}$ & $1553,90 \mathrm{a}$ & $7,55 \mathrm{a}$ & $189,73 b$ & $25,70 \mathrm{f}$ & $10,38 \mathrm{a}$ & $13,55 \mathrm{a}$ \\
\hline H09-14 & $41,62 \mathrm{a}$ & $1163,31 b$ & $7,53 \mathrm{a}$ & $252,27 \mathrm{a}$ & $28,35 \mathrm{~d}$ & $11,77 \mathrm{a}$ & $13,95 \mathrm{a}$ \\
\hline H09-15 & $38,29 a$ & $1288,29 b$ & $7,40 \mathrm{a}$ & $209,53 b$ & $33,16 b$ & $12,35 \mathrm{a}$ & $13,39 a$ \\
\hline H09-16 & $35,46 a$ & $985,33 c$ & $8,71 \mathrm{~b}$ & $253,33 a$ & $23,90 \mathrm{~g}$ & $8,36 \mathrm{~b}$ & $12,12 b$ \\
\hline H09-17 & $36,55 \mathrm{a}$ & $921,68 \mathrm{c}$ & $8,89 b$ & $280,83 a$ & $19,93 \mathrm{~h}$ & $7,33 b$ & $12,29 b$ \\
\hline H09-18 & $25,13 b$ & $740,25 \mathrm{c}$ & $9,29 b$ & $242,33 a$ & $23,25 \mathrm{~g}$ & $5,75 b$ & $11,97 \mathrm{~b}$ \\
\hline H09-19 & $37,28 \mathrm{a}$ & $1281,52 b$ & $8,21 \mathrm{~b}$ & $203,91 b$ & $27,56 \mathrm{e}$ & $10,05 \mathrm{a}$ & $11,43 b$ \\
\hline H09-20 & $36,80 \mathrm{a}$ & $1009,33 c$ & $6,01 \mathrm{a}$ & $254,92 \mathrm{a}$ & $34,78 \mathrm{a}$ & $12,93 \mathrm{a}$ & $13,68 \mathrm{a}$ \\
\hline H09-21 & $39,00 \mathrm{a}$ & $1010,84 \mathrm{c}$ & $8,40 \mathrm{~b}$ & $269,64 a$ & $19,27 \mathrm{~h}$ & $7,49 b$ & $11,47 b$ \\
\hline H09-22 & $30,36 b$ & $1004,46 c$ & $7,27 \mathrm{a}$ & $211,87 \mathrm{~b}$ & $25,54 f$ & $7,72 b$ & $11,47 b$ \\
\hline $\mathrm{H} 09-23$ & $27,88 \mathrm{~b}$ & $845,38 \mathrm{c}$ & $6,34 \mathrm{a}$ & $233,36 b$ & $29,46 \mathrm{~d}$ & $8,03 b$ & $13,70 \mathrm{a}$ \\
\hline H09-24 & $33,63 a$ & $943,60 \mathrm{c}$ & $8,19 b$ & $249,42 \mathrm{a}$ & $22,84 \mathrm{~g}$ & $7,64 b$ & $10,78 b$ \\
\hline H09-25 & $37,45 a$ & $1205,67 b$ & $7,79 \mathrm{~b}$ & $217,53 b$ & $30,05 c$ & $11,26 \mathrm{a}$ & $13,53 \mathrm{a}$ \\
\hline H09-26 & $37,34 a$ & $1120,98 b$ & $8,03 \mathrm{~b}$ & $235,80 \mathrm{~b}$ & $24,57 f$ & $9,06 \mathrm{~b}$ & $12,93 \mathrm{a}$ \\
\hline H09-27 & $36,33 a$ & $944,52 \mathrm{c}$ & $7,99 b$ & $269,80 \mathrm{a}$ & $26,66 \mathrm{e}$ & $9,82 \mathrm{a}$ & $11,80 \mathrm{~b}$ \\
\hline H09-28 & $31,26 \mathrm{~b}$ & $764,73 c$ & $7,68 \mathrm{a}$ & $286,53 \mathrm{a}$ & $25,59 \mathrm{f}$ & $8,08 b$ & $13,09 \mathrm{a}$ \\
\hline H09-29 & $33,88 \mathrm{a}$ & $984,00 \mathrm{c}$ & $9,22 b$ & $241,47 \mathrm{a}$ & $25,32 f$ & $8,33 b$ & $13,16 \mathrm{a}$ \\
\hline H09-30 & $35,30 \mathrm{a}$ & $825,60 \mathrm{c}$ & $7,61 \mathrm{a}$ & $299,77 \mathrm{a}$ & $22,57 \mathrm{~g}$ & $8,10 \mathrm{~b}$ & $12,85 \mathrm{a}$ \\
\hline
\end{tabular}

'PROD: produtividade de frutos; NF: número de frutos; EC: espessura de casca; MF: massa de frutos; REND: rendimento de suco; PRSUC: produtividade de suco; e SST: teor de sólidos solúveis totais. ${ }^{2}$ Médias seguidas de letras iguais nas colunas não diferem entre si, pelo teste de Scott-Knott, a 5\% de probabilidade. 
TABELA 3- Estimativas dos coeficientes de correlação genotípica $\left(\mathrm{r}_{\mathrm{g}}\right)$ para sete características agronômicas avaliadas em 41 genótipos de maracujazeiro-amarelo.

\begin{tabular}{ccccccc}
\hline Características $^{1}$ & PROD & NF & EC & MF & REND & PRSUC \\
\hline PROD & - & & & & & \\
NF & 0,78 & - & & & & \\
EC & 0,17 & $-0,12$ & - & & & \\
MF & $-0,02$ & $-0,63$ & 0,42 & - & & \\
REND & 0,51 & 0,48 & $-0,66$ & $-0,22$ & - & \\
PRSUC & 0,81 & 0,68 & $-0,36$ & $-0,15$ & 0,92 & - \\
SST & 0,28 & 0,15 & $-0,19$ & 0,06 & 0,82 & 0,69 \\
\hline
\end{tabular}

'PROD: produtividade de frutos; NF: número de frutos; EC: espessura de casca; MF: massa de frutos; REND: rendimento de suco; PRSUC: produtividade de suco; e SST: teor de sólidos solúveis totais.

TABELA 4- Estimativas da média dos genótipos avaliados $\left(\overline{\mathrm{X}}_{\mathrm{A}}\right)$ e selecionados $\left(\overline{\mathrm{X}}_{\mathrm{s}}\right)$, e dos ganhos percentuais - GS(\%), com base na seleção simultânea, em sete características agronômicas, em genótipos de maracujazeiro-amarelo.

\begin{tabular}{cccccccc}
\hline \multirow{2}{*}{ Característica $^{1}$} & \multicolumn{3}{c}{ Índice baseado na soma de postos } & & \multicolumn{3}{c}{ Distância genótipo-ideótipo } \\
\cline { 2 - 3 } \cline { 6 - 7 } & $\overline{\mathrm{X}}_{\mathrm{A}}$ & $\overline{\mathrm{X}}_{\mathrm{s}}$ & $\mathbf{G S}(\%)$ & & $\overline{\mathrm{X}}_{\mathrm{A}}$ & $\overline{\mathrm{X}}_{\mathrm{s}}$ & GS(\%) \\
\hline PROD & 33,90 & 40,37 & 11,06 & & 33,90 & 38,72 & 8,23 \\
NF & 1022,60 & 1238,20 & 15,59 & & 1022,60 & 1059,38 & 2,66 \\
EC & 7,65 & 6,85 & $-6,72$ & & 7,65 & 6,98 & $-5,63$ \\
MF & 236,49 & 232,14 & $-1,28$ & & 236,49 & 258,95 & 6,59 \\
REND & 28,07 & 32,43 & 7,41 & & 28,07 & 33,74 & 9,64 \\
PRSUC & 9,48 & 13,03 & 25,02 & & 9,48 & 13,00 & 24,78 \\
SST & 12,98 & 14,03 & 5,10 & & 12,98 & 13,84 & 4,16 \\
\hline
\end{tabular}

${ }^{1}$ PROD: produtividade de frutos; NF: número de frutos; EC: espessura de casca; MF: massa de frutos; REND: rendimento de suco; PRSUC: produtividade de suco; e SST: teor de sólidos solúveis totais.

TABELA 5- Genótipos de maracujazeiro-amarelo selecionados pelos índices de seleção, baseado na soma de postos (SP) e/ou distância genótipo-ideótipo (DGI).

\begin{tabular}{|c|c|c|c|c|c|c|c|c|}
\hline \multirow{2}{*}{ Genótipos } & \multicolumn{7}{|c|}{ Características $^{1}$} & \multirow{2}{*}{ Índice } \\
\hline & PROD & NF & EC & MF & REND & PRSUC & SST & \\
\hline H09-03 & 34,16 & 830,89 & 6,87 & 290,05 & 34,12 & 11,67 & 13,99 & DGI \\
\hline H09-05 & 37,25 & 1025,88 & 7,85 & 254,87 & 35,16 & 12,94 & 12,40 & DGI \\
\hline H09-08 & 41,41 & 1462,59 & 6,67 & 201,36 & 29,58 & 12,43 & 13,96 & SP \\
\hline H09-10 & 43,75 & 1267,50 & 6,63 & 242,62 & 36,27 & 15,68 & 15,16 & $\mathrm{SP}+\mathrm{DGI}$ \\
\hline H09-14 & 41,62 & 1163,31 & 7,53 & 252,27 & 28,35 & 11,77 & 13,95 & $\mathrm{SP}+\mathrm{DGI}$ \\
\hline H09-15 & 38,29 & 1288,29 & 7,40 & 209,53 & 33,16 & 12,35 & 13,39 & SP \\
\hline H09-20 & 36,80 & 1009,33 & 6,01 & 254,92 & 34,78 & 12,93 & 13,68 & $\mathrm{SP}+\mathrm{DGI}$ \\
\hline
\end{tabular}

${ }^{1}$ PROD: produtividade de frutos; NF: número de frutos; EC: espessura de casca; MF: massa de frutos; REND: rendimento de suco; PRSUC: produtividade de suco; e SST: teor de sólidos solúveis totais. 


\section{CONCLUSÕES}

1- Foram identificados pelo menos quatro híbridos de maracujazeiro-amarelo (H09-08, H0910, H09-13 e H09-14) que apresentam médias de produtividades de frutos acima de 40 t.ha $^{-1}$.

2- Os híbridos H09-10, H09-14 e H0920 possuem bom equilíbrio para as principais características, como PROD, NF, MP, REND, PRSUC e SST.

\section{AGRADECIMENTOS}

À Fundação de Amparo à pesquisa do Estado da Bahia (Fapesb), ao Conselho Nacional de Desenvolvimento Científico e Tecnológico (CNPq) e à Coordenação de Aperfeiçoamento de Pessoal de Nível Superior (CAPES), pelo apoio financeiro à pesquisa e concessão das bolsas de estudo.

\section{REFERÊNCIAS}

ALBUQUERQUE, I.C. de; CAVALCANTE, L.F; LOPES, E.B.; ARAÚJO R. da C.; BRITO, C.H. de. Efeito de diferentes podas em ramos produtivos no rendimento do maracujazeiro amarelo. Engenharia Ambiental, Espírito Santo do Pinhal, v.6, n.3, p.577593, 2009.

CAMPOS, V.B.; Cavalcante, L.F.; Dantas, T.A.G.; Mota, J.K. de M; Rodrigues, A.C.; Diniz, A.A. Caracterização física e química de frutos de maracujazeiro amarelo sob adubação potássica, biofertilizante e cobertura morta. Revista Brasileira de Produtos Agroindustriais, Campina Grande, v.9, n.1, p.59-71, 2007.

CRUZ, C.D. Programa genes: estatística experimental e matrizes. Viçosa: Editora da UFV, 2006. 285p.

FARIAS, M.A.A.; FARIA, G.A.; CUNHA, M.A.P.; PEIXOTO, C.P.; SOUSA, J.S. Caracterização física e química de frutos de maracujá amarelo de ciclos de seleção massal estratificada e de populações regionais. Magistra, Cruz das Almas, v.17, n.2, p.83-87, 2005.
FREITAS, J.P.X.; OLIVEIRA, E.J.; JESUS, O.N.; CRUZ NETO, A.J.; SANTOS, L.R. Formação de população base para seleção recorrente em maracujazeiro-amarelo com uso de índices de seleção. Pesquisa Agropecuária Brasileira, Brasília, v.47, p.393-401, 2012.

FREITAS, J.P.X.; OLIVEIRA, E.J.; CRUZ NETO, A.J.; SANTOS, L.R. Avaliação de recursos genéticos de maracujazeiro-amarelo. Pesquisa Agropecuária Brasileira, Brasília, v.46, n.9, p.1013-1020, 2011.

GONÇALVES, G.M.; PIO VIANA, A.; BEZERRA NETO, F.V.; PEREIRA, M.G.; PEREIRA, T.N.S. Seleção e herdabilidade na predição de ganhos genéticos em maracujá-amarelo. Pesquisa Agropecuária Brasileira, Brasília, v.42, p.193-198, 2007.

HAFLE, O.M.; RAMOS, J.D.; LIMA, L.C. de O.; FERREIRA, E.A.; MELO, P.C. de. Produtividade e qualidade de frutos do maracujazeiro-amarelo submetido à poda de ramos produtivos. Revista Brasileira de Fruticultura, Jaboticabal, v.31, n.3, 763-770, 2009.

MELETTI, L.M.M.; SANTOS, R.R. dos; MINAMI, K. Melhoramento do maracujazeiro-amarelo: obtenção do cultivar 'COMPOSTO IAC-27'. Scientia Agrícola, Piracicaba, v.57. n.3, p.491-498, 2000.

MULAMBA, N.N.; MOCK, J.J. Improvement of yield potential of the Eto Blanco maize (Zea mays L.) population by breeding for plant traits. Egyptian Journal of Genetics and Cytology, Alexandria, v.7, p.40-51, 1978.

NASCIMENTO, T.B. do; RAMOS, J.D.; MENEZES, J.B. Características físicas do maracujá-amarelo produzido em diferentes épocas. Pesquisa Agropecuária Brasileira, Brasília, v.34, n.12, p.2353-2358, 1999.

NASCIMENTO, W.M.O.; TOMÉ, A.T.; OLIVEIRA, M.S.P.; MÜLLER, C.H.; CARVALHO, J.E.U. Seleção de progênies de maracujazeiro-amarelo (Passiflora edulis f. flavicarpa) quanto à qualidade de frutos. Revista Brasileira de Fruticultura, Jaboticabal, v.25, n.1, p. 186-188, 2003. 
NEGREIROS, J.R. da S.; ARAÚJO NETO, S.E. de; ÁLVARES, V. de S.; LIMA, V.A. de.; OLIVEIRA, T.K. de. Caracterização de frutos de progênies de meios-irmãos de maracujazeiro-amarelo em Rio Branco, Acre. Revista Brasileira de Fruticultura, Jaboticabal, v.30, n.2, p.431-437, 2008.

OLIVEIRA, E.J.; SANTOS, V.S.; LIMA, D.S.; MACHADO, M.D.; LUCENA, R.S; MOTTA, T.B.N.; CASTELLEN, M.S. Seleção em progênies de maracujazeiro-amarelo com base em índices multivariados. Pesquisa Agropecuária Brasileira, Brasília, v.43, n.11, p.1543-1549, 2008.

OLIVEIRA, E.J.; SANTOS, V.S.; LIMA, D.S.; MACHADO, M.D.; LUCENA, R.S; MOTTA, T.B.N. Estimativas de correlações genotípicas e fenotípicas em germoplasma de maracujazeiro. Bragantia, Campinas, v.70, n.2, p.255-261, 2011.
SANTOS, F.S.; AMARAL JÚNIOR, A.T.; FREITAS JÚNIOR, S. de P.; RANGEL, R.M.; PEREIRA, M.G. Predição de ganhos genéticos por índices de seleção na população de milho-pipoca UNB-2U sob seleção recorrente. Bragantia, Campinas, v.66, p.389-396, 2007.

SILVA, M.G.M.; VIANA, A.P.; GONÇALVES, G.M.; AMARAL JÚNIOR, A.T.; PEREIRA, M.G. Seleção recorrente intrapopulacional no maracujazeiro amarelo: alternativa de capitalização de ganhos genéticos. Ciência e Agrotecnologia, Lavras, v.33, n.1, p.170-176, 2009. 